\title{
FLAVONOID DISTRIBUTION IN FOUR VARIETIES OF Ficus deltoidea (JACK)
}

\author{
Syazwani Dzolin ${ }^{1}$, Rohaya Ahmad², Mazatulikhma Mat Zain ${ }^{3}$, Mohd Ikhwan Ismail ${ }^{4}$ \\ ${ }^{1}$ Faculty of Applied Sciences, Universiti Teknologi MARA, 40450 Shah Alam, Selangor, Malaysia \\ syazwani@frim.gov.my \\ ${ }^{2}$ Atta-ur-Rahman Institute for Natural Product Discovery, Universiti Teknologi MARA, 42300 Bandar \\ Puncak Alam, Selangor, Malaysia. \\ rohayaahmad@salam.uitm.edu.my \\ ${ }^{3}$ Institute of Science (IOS), Universiti Teknologi MARA, 40450 Shah Alam, Selangor, Malaysia. \\ mazatul70@gmail.com \\ ${ }^{4}$ PROMISE, Faculty of Pharmacy, Universiti Teknologi MARA, 42300 Bandar Puncak Alam, \\ Selangor, Malaysia.
}

\begin{abstract}
We have previously reported the antioxidant and neuroprotective activities of the aqueous extract of four varieties of Ficus deltoidea $(F d)$ (Moraceae) namely var kunstleri $(F d v k)$, var angustifolia ( $F d v a)$, var deltoidea $(F d v d)$ and var intermedia $(F d v i)$. In this study, flavonoid constituents in aqueous leaf and fig extracts of the four varieties were analyzed and characterized using liquid chromatography mass spectrometer quadrupole-time of flight (LCMS-Q-TOF) via hierarchical cluster analysis (HCA) technique. The HCA dendrogram revealed that the abundant flavonoids among the eight samples are epicatechin, quercetin-3-rutinoside, quercetin 5,4'-di-O-beta-D-glucopyranoside, myricetin and naringenin. The study found that the distribution of the flavonoids differed between the four varieties and varied within the plant parts. To date, the flavonoid distribution of the different plant parts of the four varieties has not been documented. A positive correlation was observed between flavonoid constituents present and radical scavenging activities of the aqueous extracts.
\end{abstract}

\section{Keywords}

Ficus deltoidea ( $F d$ ); Flavonoid, Liquid Chromatography Mass Spectrometer Quadrupole-Time of Flight (LCMS-Q-TOF); Hierarchical Cluster Analysis (HCA)

\section{Academic Discipline And Sub-Disciplines}

Natural Products Chemistry

\section{SUBJECT CLASSIFICATION}

Chemistry Subject Classification

\section{TYPE (METHOD/APPROACH)}

Experimental Study-Analytical Method

\section{Council for Innovative Research}

Peer Review Research Publishing System

Journal: Journal of Advances in Chemistry

Vol. 11, No. 1

editorjaconline@gmail.com

www.cirjac.com 


\section{INTRODUCTION}

Ficus deltoidea (Mas Cotek) has long been used as traditional medicine in Malaysia and exists in seven varieties [39]. Malay traditional practitioners extensively consume Mas Cotek as tea. It is also used both externally and internally to treat an extensive list of conditions; including wounds, headache, fever [20], diabetes [31], toothache and as herbal drink for women to strengthen the uterus after childbirth [27] as well as other diseases related to oxidative stress. The reported biological activities of this plant include antioxidant, antihyperglycemic, anti-inflammatory, antiulcerogenic and antinociceptive ([36]; [15]; [26]; [27]; [2]). [2] reported that almost all of the parts of Fd plant including the root, bark, leaf and fig have their own medicinal properties. Previous studies on the aqueous extracts showed that it contained antioxidant flavonoids including flavan-3-ol monomers namely catechin, epicatechin, gallocatechin and epigallocatechin [22]. It was earlier reported to contain polyphenols, flavonoids and tannins but was absent of alkaloids, triterpenes and saponins ([38] [9]).

[33] have reported flavonoids as the antioxidant scavengers of a wide range of ROS and inhibitors of lipid peroxidation. This class of natural products represents the most abundant antioxidants in the diet and they have gained tremendous interest as potential therapeutic agents against a wide variety of diseases, most of which involve oxidant damage [25] Flavonoids may interfere in several of the steps that lead to the development of malignant tumors, including protecting DNA from oxidative damage, inhibiting carcinogen activation, and activating carcinogen-detoxifying systems [7,13].

Today, liquid chromatography mass spectrometer quadrupole-time of flight (LCMS-Q-TOF) has been shown to be a powerful tool in the search of new biomarkers for disease and drugs. Analysed data from LCMS-Q-TOF has been used to examine the untargeted metabolites in plant samples and to find the ones with statistically significant variations in abundance within a set of experimental versus internal and external database [29]. In analysing LCMS-Q-TOF data, hierarchical clustering analysis (HCA) is an accurate technique in which results are represented as a two-dimensional diagram known as a dendrogram. HCA demonstrate a clear clusterisation of plant specimens selecting the highest discriminating ions given by the complete data analysis and this lead to the specific identification of metabolites [12].

Continuing our interest in the biological activities of the plant, this study was aimed at identifying flavonoids in the aqueous leaf and fig extracts of four varieties of Fd namely var angustifolia ( Fdva), var deltoidea ( Fdvd), var intermedia (Fdvi), and var kunstleri (Fdvk) via LCMS-Q-TOF method. Distribution of the flavonoids was determined by HCA technique and correlation of flavonoid constituent and radical scavenging activities was made.

\section{METHODOLOGY}

\section{Plant Materials}

The fresh leaf and fig of four varieties of Fd namely Fdvk, Fdva, Fdvd, and Fdvi, were collected from Kuala Pilah, Negeri Sembilan, Malaysia and were identified by Mr. Kamarudin Saleh (botanist) from Forest Research Institute Malaysia (FRIM). The samples were cleaned, dried under room temperature and finely ground. $100 \mathrm{~g}$ of each ground sample was heated separately in $500 \mathrm{ml}$ of distilled water by continuous stirring at $60^{\circ} \mathrm{C}$ for 1 hour. The aqueous extracts were then filtered, concentrated under reduced pressure and stored at $-20^{\circ} \mathrm{C}$ before being subjected to further analysis.

\section{Determination of Antioxidant Activities of the Aqueous Extracts}

\subsubsection{Total Flavonoids Content (TFC) Assay}

Total flavonoids content were measured by a colorimetric assay developed by [37]. A $1 \mathrm{ml}$ aliquot of appropriately diluted sample or standard solutions of catechin $(20,40,60,80$, and $100 \mathrm{mg} / \mathrm{ml})$ was added to a $10 \mathrm{ml}$ volumetric flask containing $4 \mathrm{ml}$ distilled water. At zero time, $0.3 \mathrm{ml} 5 \% \mathrm{NaNO}_{2}$ was added to the flask. After 5 minutes, $0.3 \mathrm{ml} 10 \% \mathrm{AlCl}_{3}$ was added. At 6 minutes, $2 \mathrm{ml} 1 \mathrm{M} \mathrm{NaOH}$ was added to the mixture. Immediately, the reaction flask was diluted to volume with the addition of $2.4 \mathrm{ml}$ of distilled water and thoroughly mixed. Absorbance of the pink coloured mixture was determined at 510 $\mathrm{nm}$ against water blank. Total flavonoid of extract was expressed in milligram catechin equivalents (mg CE/g extract). All analyses were run in three replicates and mean values were recorded.

\subsubsection{1,1-diphenyl-2-picrylhydrazyl (DPPH) Radical Scavenging Assay}

This assay was carried out as described by [28] with some modification [4]. Stock solutions of crude extracts were prepared as $1 \mathrm{mg} / \mathrm{ml}$ in methanol. The solutions were diluted to different concentrations $(250,125,62.5 \mathrm{and} 31.3 \mu \mathrm{g} / \mathrm{ml}$ in methanol) in a 96-well microtiter plate. Then, $5 \mu$ of DPPH solution (prepared as $10 \mathrm{mg} / \mathrm{ml}$ in methanol) were added to each well. The plate was shaken gently and placed in the dark for 30 minutes at room temperature. The absorbance was then measured at $517 \mathrm{~nm}$. Percentage of inhibition was calculated using the following formula:

$\%$ Inhibition $=\frac{\text { Abs (control) }- \text { Abs }(\text { sample })}{\text { Abs }(\text { control })} \times 100 \%$ 


\section{Identification of Compounds Using LCMS Q-TOF Analysis}

\subsubsection{Liquid Chromatography Conditions}

Chromatography was performed on Liquid Chromatography of 1200 Rapid Resolution Series (Agilent Technologies, Santa Clara, CA, USA) consisting of a binary pump, degasser, 96-well plate autosampler with thermostat, thermostat column compartment and 6520 Q-TOF mass spectrometer equipped with a dual-ESI source. The column used was a Zorbax Eclipse Plus $\mathrm{C}_{18}$ with column ID of $1.8 \mu \mathrm{m}$ particle size and $2.1 \times 100 \mathrm{~mm}$ column dimensions [3]. The temperature was maintained at $40^{\circ} \mathrm{C}$ during the run.

\subsubsection{Solvent System Conditions}

The mobile phase (A) consisted of $0.1 \%$ formic acid (Supelco, Inc) in water and (B) $0.1 \%$ formic acid in acetonitrile. The flow rate was $0.25 \mathrm{~mL} / \mathrm{min}$ and the injection volume was $2 \mu \mathrm{L}$. A linear gradient was developed over 36 minutes from $5 \%$ to $95 \%$ of mobile phase (B). Total run time was 48 minutes for each analysis. ESI source settings were as follows: $V$ Cap $4000 \mathrm{~V}$, skimmer $65 \mathrm{~V}$ and fragmentor $125 \mathrm{~V}$.

\subsubsection{Mass Spectral Conditions}

Mass spectral acquisition range selected was from 50 to $1700 \mathrm{~m} / \mathrm{z}$. The nebulizer was set at 45 psig and the drying gas nitrogen was set at a flow rate of $12 \mathrm{~L} / \mathrm{min}$. Drying gas temperature was maintained at $350^{\circ} \mathrm{C}$. Data was acquired at a rate of $2.5 \mathrm{spectra} / \mathrm{second}$ with a stored mass range of 50 to $1000 \mathrm{~m} / \mathrm{z}$. Internal reference ions were used to correct mass accuracy. Autocalibration parameters were chosen to average five scans and reference mass correction was enabled throughout the run.

\section{RESULTS AND DISCUSSION}

\subsection{Determination of Total Flavonoids Content (TFC) and Radical Scavenging Activities of the Aqueous Extracts}

The total flavonoids content in the aqueous extracts of each of the four variety was determined through a linear catechin standard curve $\left(\mathrm{y}=0.002 \mathrm{x}+0.014 ; R^{2}=0.999\right)$ where $\mathrm{x}$ is the catechin concentration $\mathrm{in} \mathrm{mg} / \mathrm{L}$ and $\mathrm{y}$ is the absorbance reading at $510 \mathrm{~nm}$. The total flavonoids content of each extract of the four varieties of Fd were expressed in mg catechin/g extract or (mg CE/g extract). Table 1 shows the TFC of extracts of the plant varieties. The leaf extract of Fdvd showed the highest TFC (362.25 mg CE/g extract) followed by Fdvi (63.25 mg CE/g extract), Fdvk (52.65 mg CE/g extract), and Fdva (26.6 mg CE/g extract). The TFC values of the fig extract were exhibited in following order: Fdvd > Fdvi $>$ Fdva $>$ Fdvk. Among the varieties, Fdvi and Fdvd showed high TFC compared to Fdvk and Fdva. Furthermore, the fig extract of each variety showed higher TFC compared to the leaf extract. The TFC value for the leaf extract of $F d v d$ was more than fivefold higher than Fdvi. However, for the fig extract, the TFC value of Fdvd was only nearly two-fold the value of $F d v i$.

[38] studied the content of flavonoids in the aqueous leaf extract of Fdva and Fdvd using colorimetric assay. The authors found that the TFC of the aqueous leaf extract of Fdvd was higher than the value for Fdva with 42.63 and $27.35 \mathrm{mg}$ quercetin/g extract, respectively. Their results showed the same trend as found in our study (89.75 and $61.10 \mathrm{mg}$ GAE/g extract for Fdvd and Fdva, respectively) with TFC value of Fdvd about 1.5 times higher than Fdva. The TFC values of the aqueous extracts of previous studies may be different with our study due to the employment of quercetin as a standard instead of catechin.

Table 1. Total Flavonoids Content of Aqueous Extracts of Four Fd Varieties

\begin{tabular}{lll}
\hline Fd Variety & Part & TFC (mg CE/g extract) \\
\hline Fdvk & Leaf & $52.65^{\mathrm{a}}$ \\
& Fig & $178.10^{\mathrm{a}}$ \\
Fdva & Leaf & $26.60^{\mathrm{b}}$ \\
& Fig & $183.90^{\mathrm{b}}$ \\
Fdvd & Leaf & $362.30^{\mathrm{a}}$ \\
& Fig & $742.60^{\mathrm{b}}$ \\
Fdvi & Leaf & $63.25^{\mathrm{b}}$ \\
& Fig & $357.60^{\mathrm{a}}$ \\
\hline
\end{tabular}

Value was expressed in mean \pm standard deviation (SD), $(n=3)$; Pearson correlation: ${ }^{a} p<0.05 ;{ }^{b} p<0.01$ 
As shown in Table 2, among the extracts tested, the leaf and fig extracts of Fdvd and the fig extract of Fdvi were found to be strong free radical scavengers with $\mathrm{IC}_{50}$ values of $15.6,7.8$ and $7.8 \mu \mathrm{g} / \mathrm{ml}$, respectively. However, only moderate radical scavenging activity was found for the leaf extract of $F d v i$ with an $\mathrm{IC}_{50}$ value of $31.3 \mu \mathrm{g} / \mathrm{ml}$ consistent with its TFC value, which is more than five times lower than its fig extract. The DPPH radical scavenging activity at most concentrations was found to correlate well with the TFC values. This is illustrated for the leaf and fig extract of Fdvd and Fdvi varieties at IC 50 value of $3.9,7.8$ and $15.6 \mu \mathrm{g} / \mathrm{ml}$ with values of the correlation coefficient $\left(R^{2}\right)$ of 0.6284 . To date, no report has been found on the radical scavenging activity of the aqueous extract on any of the varieties of $F d$. However, a study on methanolic extracts of F.microcarpa found DPPH radical scavenging activity of 7.3 and $21.4 \mu \mathrm{g} / \mathrm{ml}$ of fruits and leaf, respectively [6]. These values are comparable to the values found in our study.

Table 2. Radical Scavenging Activity (\%) of the Varieties of Fd

\begin{tabular}{|c|c|c|c|c|c|c|c|c|c|}
\hline \multirow[t]{2}{*}{ Fd variety } & \multirow[t]{2}{*}{$\begin{array}{l}\text { Plant } \\
\text { part }\end{array}$} & \multicolumn{3}{|c|}{$\begin{array}{c}\text { Sample } \\
\text { concentrations }\end{array}$} & \multirow[b]{2}{*}{$\begin{array}{l}31.3 \\
\mu \mathrm{g} / \mathrm{ml}\end{array}$} & \multirow[b]{2}{*}{$\begin{array}{l}62.5 \\
\mu \mathrm{g} / \mathrm{ml}\end{array}$} & \multirow[b]{2}{*}{$\begin{array}{l}125 \\
\mu \mathrm{g} / \mathrm{ml}\end{array}$} & \multirow[b]{2}{*}{$\begin{array}{l}250 \\
\mu \mathrm{g} / \mathrm{ml}\end{array}$} & \multirow[t]{2}{*}{$\begin{array}{l}\mathrm{IC}_{50} \\
(\mu \mathrm{g} / \mathrm{ml})\end{array}$} \\
\hline & & $\begin{array}{l}3.9 \\
\mu \mathrm{g} / \mathrm{ml}\end{array}$ & $\begin{array}{l}7.8 \\
\mu \mathrm{g} / \mathrm{ml}\end{array}$ & $\begin{array}{l}15.6 \\
\mu \mathrm{g} / \mathrm{ml}\end{array}$ & & & & & \\
\hline \multirow[t]{2}{*}{ Fdvk } & Leaf & 25.67 & 28.37 & 31.07 & 54.32 & 56.32 & 64.43 & 71.98 & $\mathrm{Na}$ \\
\hline & Fig & 20.03 & 24.32 & 27.53 & 34.06 & 39.87 & 48.28 & 60.7 & $\mathrm{Na}$ \\
\hline \multirow[t]{2}{*}{ Fdva } & Leaf & 28.67 & 35.76 & 38.94 & 52.96 & 55.96 & 59.56 & 73.18 & $\mathrm{Na}$ \\
\hline & Fig & 25.86 & 37.97 & 46.74 & 49.43 & 50.08 & 52.42 & 56.54 & $\mathrm{Na}$ \\
\hline \multirow[t]{2}{*}{ Fdvd } & Leaf & 18.54 & 41.18 & 51.11 & 73.51 & 74.5 & 76.23 & 82.04 & 15.6 \\
\hline & Fig & 34.92 & 47.19 & 48.85 & 61.93 & 67.16 & 71.88 & 81.43 & 7.8 \\
\hline Fdvi & Leaf & 19.99 & 44.46 & 55.03 & 75.52 & 77.18 & 78.59 & 80.17 & 31.3 \\
\hline & Fig & 48.31 & 49.64 & 53.85 & 64.97 & 68.57 & 74.56 & 78.13 & 7.8 \\
\hline $\begin{array}{l}{ }^{*} \text { F.microca } \\
\text { rpa }\end{array}$ & $\begin{array}{l}\text { Leaf } \\
\text { Fruit }\end{array}$ & & & & & & & & $\begin{array}{l}21.4 \\
7.3\end{array}$ \\
\hline Quercetin & & 68.6 & 69.2 & 71.18 & 72.29 & 73 & 73.42 & 75.29 & $\mathrm{Nd}$ \\
\hline$\alpha$-tocopherol & & 74.92 & 80.72 & 82.3 & 83.32 & 83.9 & 83.96 & 84.69 & $\mathrm{Nd}$ \\
\hline
\end{tabular}

Value was expressed in mean \pm standard deviation (SD), $(n=3)$. Na, Not active; Nd, Not detectable in experimental concentration range $(3.9-250 \mu \mathrm{g} / \mathrm{ml})$; strong radical scavenging activity, $\left(\mathrm{IC}_{50}<30 \mu \mathrm{g} / \mathrm{ml}\right)$; moderate radical scavenging activity, $\left(30 \mu \mathrm{g} / \mathrm{ml} \leq \mathrm{IC}_{50} \leq 100 \mu \mathrm{g} / \mathrm{ml}\right)$; weak radical scavenging activity, $\left(\mathrm{IC}_{50}>100 \mu \mathrm{g} / \mathrm{ml}\right)[1]$.

${ }^{*}$ The $\mathrm{IC}_{50}$ values found in methanolic extract of Ficus microcarpa [6].

\subsection{Identification of Compounds Present in the Aqueous Leaf and Fig Extracts of Four Varieties of Fd}

The leaf and fig aqueous extracts of the four varieties of $F d$ were analyzed by gradient reverse phase liquid chromatography (LC) with Q-TOF MS detection. The identification was confirmed by internal and external standards. In this study, five flavonoid compounds detected were epicatechin, quercetin-3-rutinoside, myricetin, naringenin and quercetin 5,4'-di-O-beta- $D$-glucopyranoside using LCMS-Q-TOF via HCA technique (Table 3). 
Table 3. Mass Spectral Characteristics and Identity of Compounds Present in the Aqueous Extracts of Four Varieties of $\boldsymbol{F d}$

\begin{tabular}{|c|c|c|c|}
\hline Peak & $\begin{array}{c}t_{\mathrm{R}} \\
(\min )\end{array}$ & Compound & $\begin{array}{l}{[\mathrm{M}+\mathrm{H}]^{+}} \\
(\mathrm{m} / \mathrm{z})\end{array}$ \\
\hline 1 & 6.747 & $\begin{array}{l}\text { Epicatechin }\left[\mathrm{C}_{15} \mathrm{H}_{14} \mathrm{O}_{6}, \mathrm{db}=95.57 \text {, overall=95.57, KEGG ID=C09727, CAS }\right. \\
\mathrm{ID}=490-46-0]\end{array}$ & 291.0868 \\
\hline 2 & 9.361 & 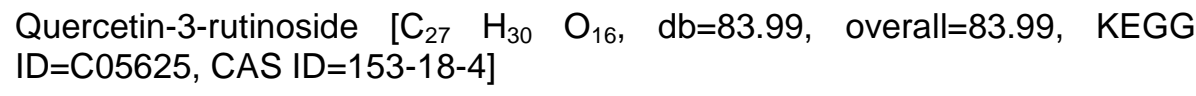 & 611.1611 \\
\hline 3 & 9.377 & Quercetin 5,4'-di-O-beta- $D$-glucopyranoside $\left[\mathrm{C}_{27} \mathrm{H}_{30} \mathrm{O}_{17}\right.$, tgt=61.06] & 627.1587 \\
\hline 4 & 9.553 & $\begin{array}{l}\text { Myricetin }\left[\mathrm{C}_{15} \mathrm{H}_{10} \mathrm{O}_{8}, \mathrm{db}=88.79 \text {, overall=88.79, KEGG ID=C10107, CAS }\right. \\
\mathrm{ID}=529-44-2]\end{array}$ & 319.0435 \\
\hline 5 & 16.062 & $\begin{array}{l}\text { Naringenin }\left[\mathrm{C}_{15} \mathrm{H}_{12} \mathrm{O}_{5}, \mathrm{db}=79.39 \text {, overall=79.39, KEGG ID=C00509, CAS }\right. \\
\mathrm{ID}=480-41-1]\end{array}$ & 273.0770 \\
\hline
\end{tabular}

$t_{R}$, retention time; $[\mathrm{M}+\mathrm{H}]^{+}$, positively charged molecular ion

A study by [22] on boiled aqueous extract of $F d$ (the variety is not specified) collected from a local market in Pahang, Malaysia had identified flavonoids such as catechin, epicatechin, gallocatechin and epigallocatechin using High Performance Liquid Chromatography (HPLC) amongst other flavonoid glycosides. The reported quantities were 98, 89, 44 and $87 \mu \mathrm{mol} / \mathrm{L}$, for catechin, epicatechin, gallocatechin and epigallocatechin respectively. However, in our study, we were not able to detect catechin, gallocatechin or epigallocatechin in any of the four varieties. Internal standards were used to confirm their absence. This might be due to differences in the origin of the sample and the method of extraction. Furthermore our method employed $60^{\circ} \mathrm{C}$ as the extracting temperature while [22] employed a temperature of $100^{\circ} \mathrm{C}$ to extract the secondary metabolites.

Peak $1\left(t_{R}, 6.747 \mathrm{~min} ;[\mathrm{M}+\mathrm{H}]^{+}\right.$at $\left.\mathrm{m} / z, 291.0868\right)$ was identified as epicatechin as shown in spectrum Fig. 1(a) and confirmed by comparison with standard. Epicatechin is a flavan-3-ol belonging to catechin family and can be found in natural products or medicinal herbs. It commonly exists in monomeric and oligomeric forms [21]. Employing the DPPH method, [22] had identified $18 \%$ antioxidant activity of epicatechin $\left(t_{R}, 19.4 \mathrm{~min} ; \mathrm{m} / \mathrm{z}, 289\right.$ [M-H] $)$ in the aqueous infusion of leaf of Fd. It showed a strong fluorescent peak using HPLC-PDA-MS ${ }^{2}$, which gave rise to $\mathrm{MS}^{2}$ ions at $m / z 245,205$, and 179. Their results were confirmed by co-chromatography with an authentic standard and it indicates that epicatechin found in Fd may be utilized as a potential antioxidant. Similarly, [6] also used DPPH method and found that epicatechin from the ethyl acetate fraction of aerial root and bark of Ficus microcarpa exhibited excellent antioxidant activity.

As shown in Fig. 1(b), peak $2\left(t_{R}, 9.361 \mathrm{~min}\right)$ indicated the presence of rutin (quercetin-3-rutinoside) $[\mathrm{M}+\mathrm{H}]^{+}$at $\mathrm{m} / \mathrm{z}$ 611.1611. Rutin is a flavonol and comprises quercetin and the disaccharide rutinose [35]. The first documented report on flavonoids profiling in different varieties of the hot and cold aqueous extracts of Fd leaf namely Fdvk and Fdva by [14] using reversed-phase HPLC reported a higher rutin content in Fdvk compared to Fdva. In contrast, the results obtained in our study indicated that the content of rutin in the aqueous extracts of $F d v k$ is similar to Fdva based on the dendrogram shown in Fig. 3. A study by [24] found that rutin have beneficial effect on spatial memory along with the concentration of brain neurotransmitters in aged rats. Rutin also showed antidiabetic potential in streptozotocin-induced diabetic istar rats as reported by [18].

Peak $3\left(t_{R}, 9.377 \mathrm{~min}\right)$ had a $[\mathrm{M}+\mathrm{H}]^{+}$at $\mathrm{m} / z 627.1587$ and was identified as quercetin $5,4^{\prime}$-di-O-beta-D-glucopyranoside as shown in Fig. 1(c). [19] had earlier reported a relative molecular mass of 626 for the compound from its FD-MS spectrum. Its aglycone, quercetin has often been proven by in vitro tests to act as a powerful antioxidant. The compound being a major constituent of the flavonoid intake, has been suggested to be a key in fighting several chronic degenerative diseases. It also exhibited a marked neuroprotective effect in in vitro experiments and this is mainly explained by its antioxidant capacity and ability to scavenge free radicals [11]. To date, there has been no comparative study reported on the quercetin or quercetin derivatives from the four varieties of $F d$.

Peak $4\left(t_{R}, 9.553 \mathrm{~min}\right)$ showed an $\mathrm{m} / \mathrm{z} 319.0435$ corresponding to $[\mathrm{M}+\mathrm{H}]^{+}$and was identified as myricetin as shown in Fig. 1 (d). Myricetin (3,3', $4^{\prime}, 5,5^{\prime}, 7$-hexahydroxylflavone) is a natural flavonol with hydroxyl substitutions at the $3,3^{\prime}, 4^{\prime}, 5,5^{\prime}$ and 7 positions [34]. A study by [8] had reported the myricetin capacity in protecting $\mathrm{PC} 12$ cells from oxidative insult $\left(\mathrm{H}_{2} \mathrm{O}_{2}\right)$ and at the same time, it increases the cell survival. A study by [32] found myricetin as the major flavonoid in the ethanolic leaf extract of Ficus carica using reversed-phase HPLC and analyzed by UV/Vis array and electrospray ionization (ESI)-mass spectrometry (MS) detectors. Interestingly, [22] who studied Fd did not find myricetin in the aqueous extract. There has also been no other report on its detection from any variety of $F d$ species.

Peak $5\left(t_{R}, 16.013 ; \mathrm{m} / \mathrm{z}, 273.0770\right)$ was identified as naringenin as shown by Fig. 1(e). Naringenin (4',5,7trihydroxyflavanone) is also known as aglycone of naringin and classified as a flavanone [23]. Naringenin extracted from the methanol leaf extract of F.benjamina was also reported to possess cytotoxicity against T-lymphoblastic leukemia (CEM-SS) cell line [5]. To date, there has been no report on the isolation or detection of this compound from Fd species. 


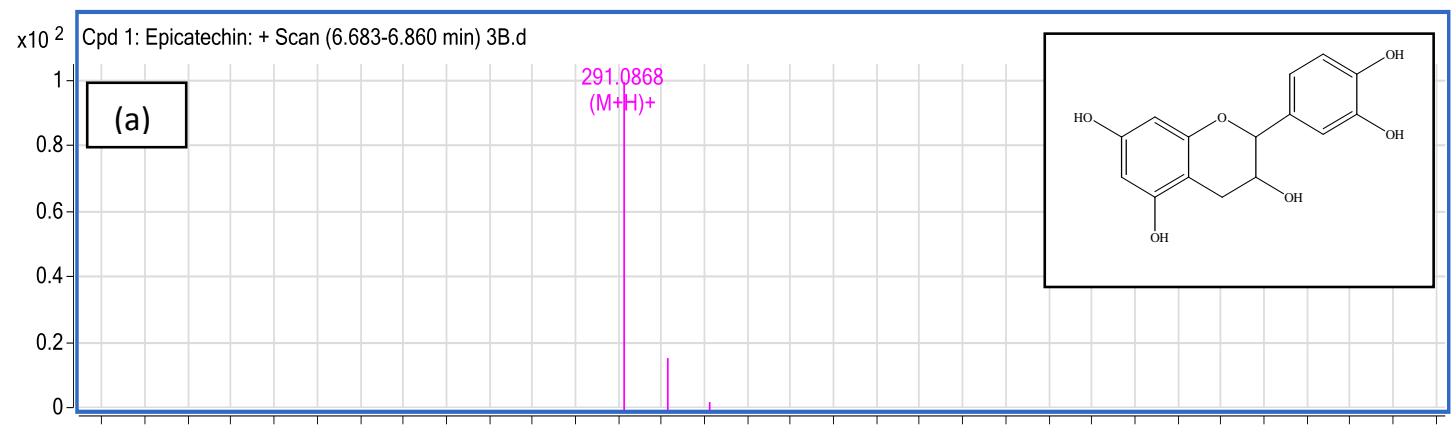

279280281282283284285286287288289290291292293294295296297298299300301302303304305306307308309 Counts (\%) vs. Mass-to-Charge (m/z)

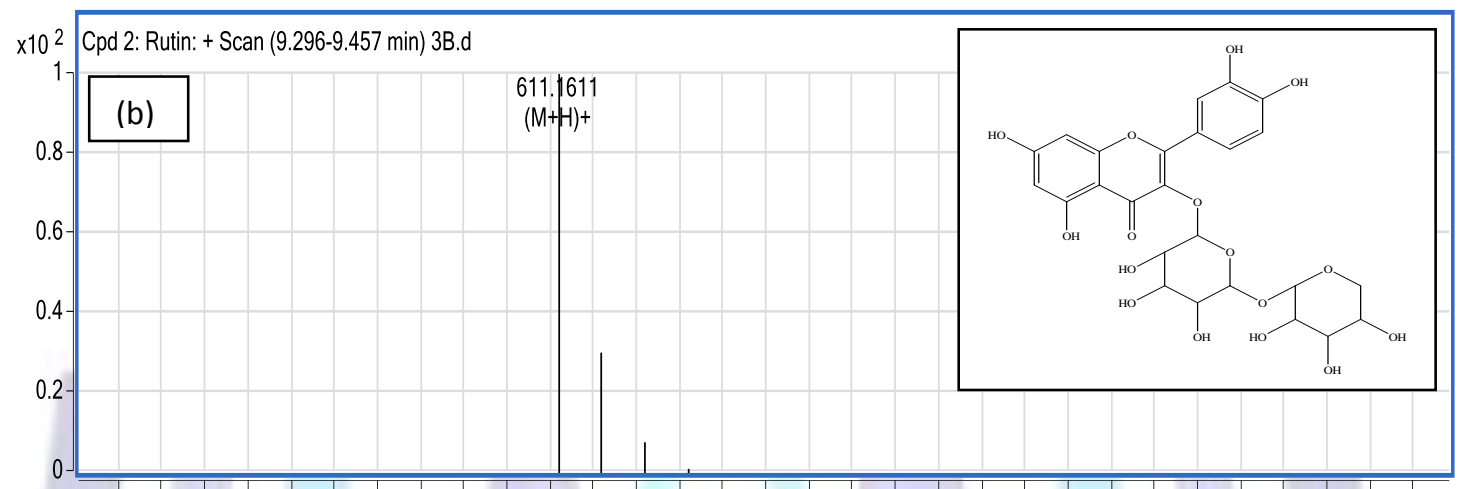

601602603604605606607608609610611612613614615616617618619620621622623624625626627628629630631 Counts (\%) vs. Mass-to-Charge (m/z)
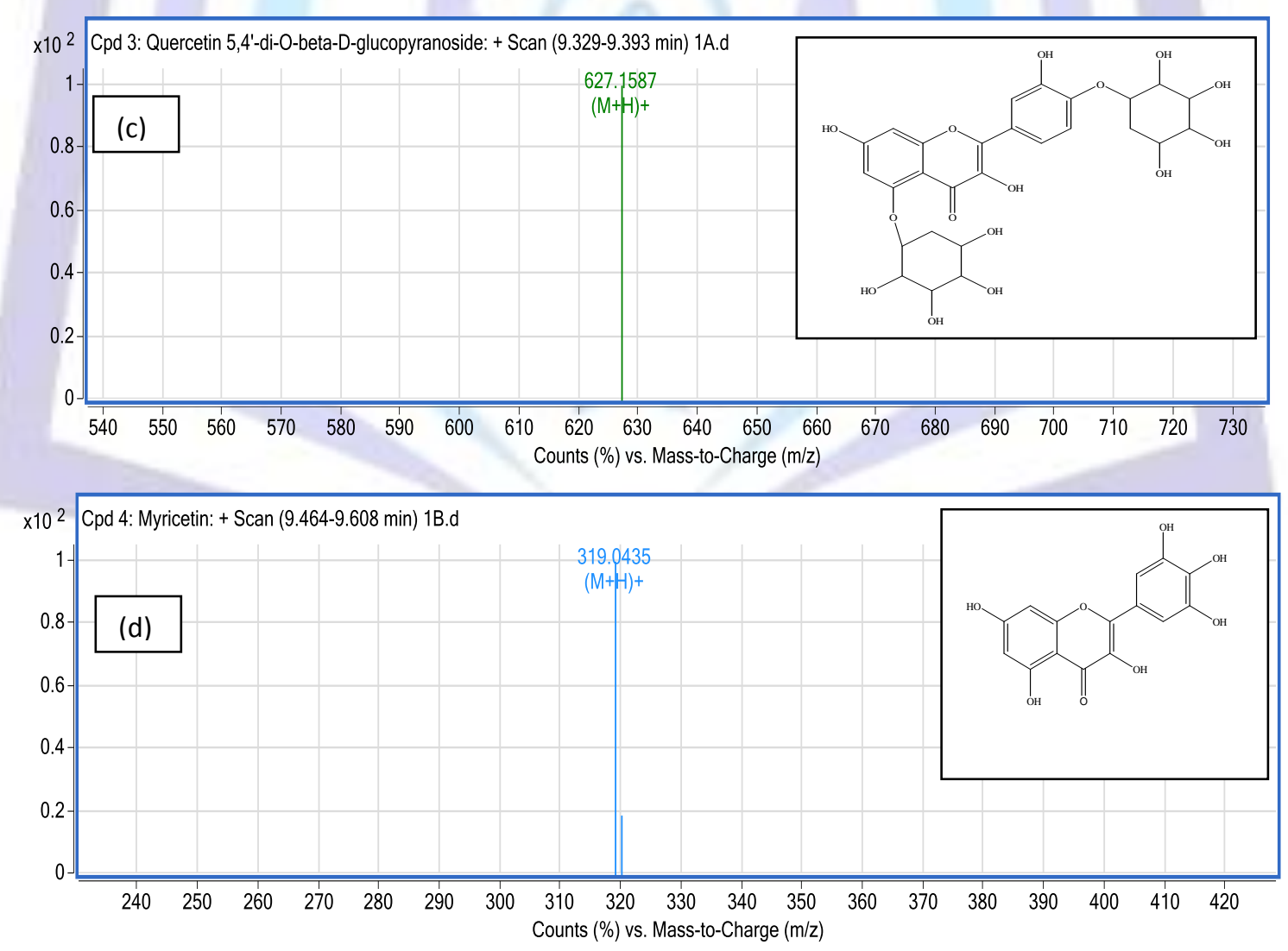


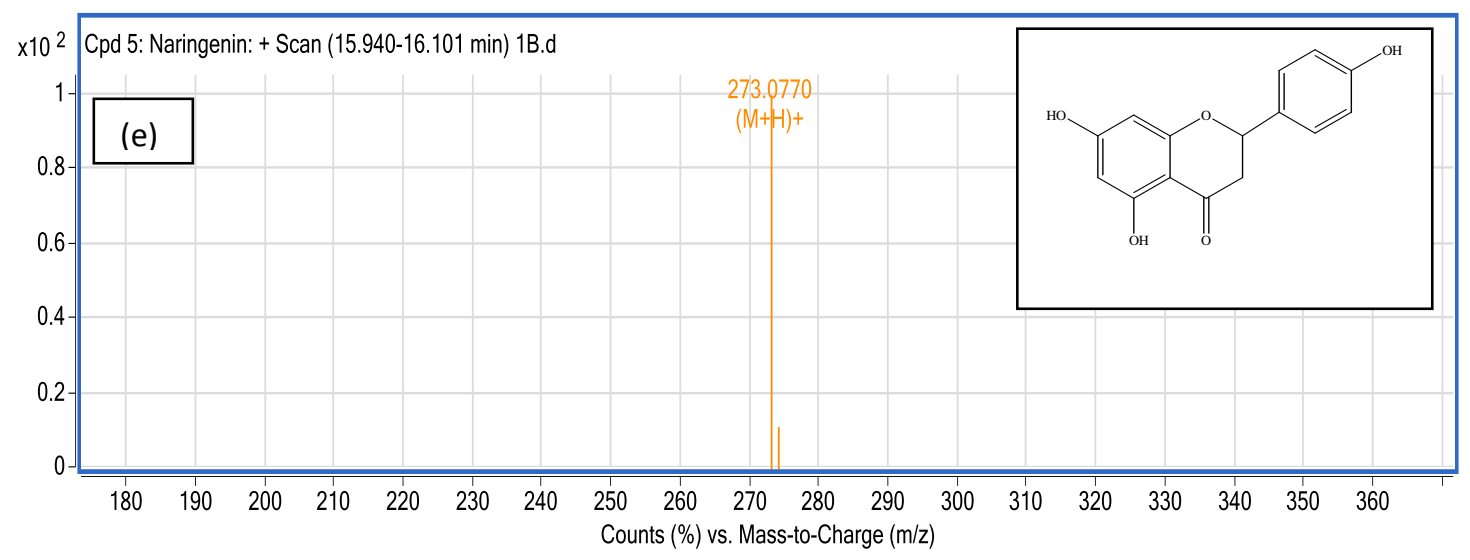

Fig. 1. LCMS Q-TOF Spectrum of (a) epicatechin, (b) quercetin-3-rutinoside, (c) quercetin 5,4'-di-O-beta-Dglucopyranoside, (d) myricetin, (e) naringenin

\subsection{Hierarchical Cluster Analysis (HCA) of Aqueous Leaf and Fig Extracts of Four Varieties of $\boldsymbol{F d}$}

HCA is the most popular clustering technique to evaluate the quality of the medicinal plants [17] and it is a simple method of grouping a set of available data based on their similarities [30]. The presentation of HCA results as a dendrogram makes it such a way the relationships can be more readily visualized. In this study, HCA using Euclidean distances and average linkage method was used for clustering its ability to separate the data into four clusters. In the dendrogram shown in Table 3, the horizontal axis represents the plant parts of the varieties while the vertical axis represents the flavonoids obtained. The clusters were classified and numbered as follows: (I) fig of Fdva and Fdvk, (II) fig of Fdvd and Fdvi, (III) leaf of Fdvd and (IV) leaf of Fdva, Fdvi and Fdvk. The identified flavonoids in this study were epicatechin, quercetin-3rutinoside, quercetin 5,4'-di-O-beta-D-glucopyranoside, myricetin and naringenin (as listed in Table 1) were grouped based on their distribution values $(0.14,0.31$ and 0.55$)$ as shown in Fig. 2.

In the first (I) cluster, the flavonoid quercetin-3-rutinoside showed the highest intensity in the fig extracts of $F d v a$ and $F d v k$ and low intensity of epicatechin, quercetin 5,4'-di-O-beta-D-glucopyranoside and naringenin. In contrast, the flavonoids epicatechin and quercetin 5,4'-di-O-beta-D-glucopyranoside exhibited the highest intensity in the fig of Fdvd and Fdvi while naringenin showed the lowest intensity in the second (II) cluster. The leaf of Fdvd was grouped alone in the third (III) cluster with the highest intensity of epicatechin and the other four flavonoids namely quercetin-3-rutinoside, quercetin 5,4'di-O-beta-D-glucopyranoside, myricetin and naringenin were indicated by low intensity. In the fourth (IV) cluster, the flavonoid naringenin exhibited the highest intensity in the leaf of Fdvk while low intensity can be observed in the distribution of epicatechin, quercetin-3-rutinoside, quercetin 5,4'-di-O-beta-D-glucopyranoside and myricetin.

To the best of our knowledge, no comparative study regarding this analysis of plant parts of the aqueous extracts of the four varieties of $F d$ has been documented. In addition, the distribution and intensity of flavonoid constituents in the aqueous leaf and fig extracts of the four varieties were seen to be consistent with their radical scavenging activities as measured by the DPPH assay. Both Fdvd and Fdvi (leaf and fig extracts) exhibited strong antioxidant potential which may be related to the high amount of epicatechin, in this plant variety. A study by [16] had reported the scavenging activity of hydroxyl groups present on ring B of flavonoids, specifically the structure 3'-4' catechol (catechol moiety). The presence of a hydroxyl group in position 3 added to the catechol structure of flavonoid (as shown in Fig. 3 ) was found to increase tenfold scavenger activity towards free radicals. 


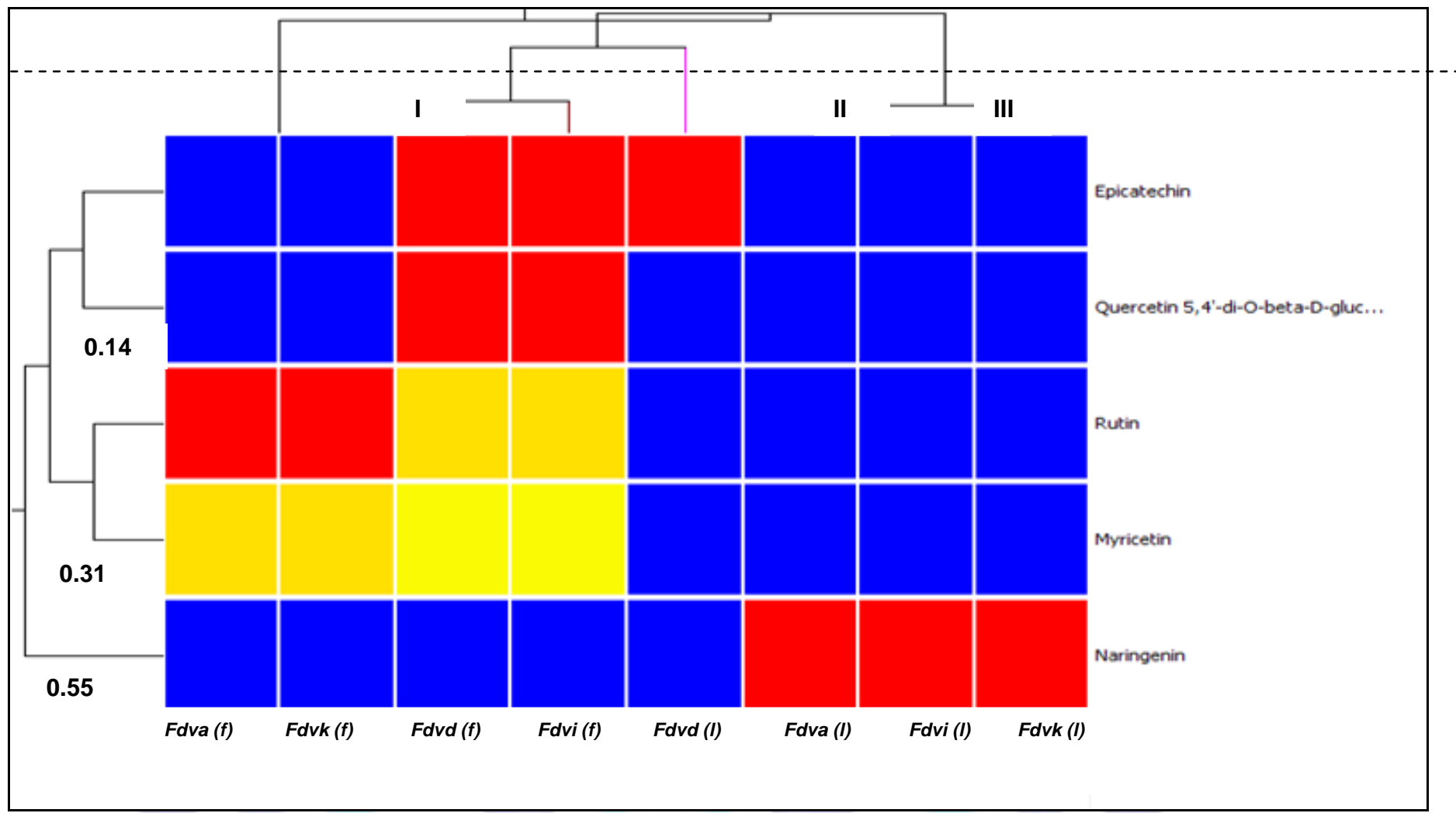

Fig. 2. HCA Dendrogram of the Compounds from the Aqueous Leaves and Figs Extracts of the Four Varieties of Fd

I=leaves; $f$ =figs

Legend - Hierarchical Combined Tree on type of plant - plant part Color range

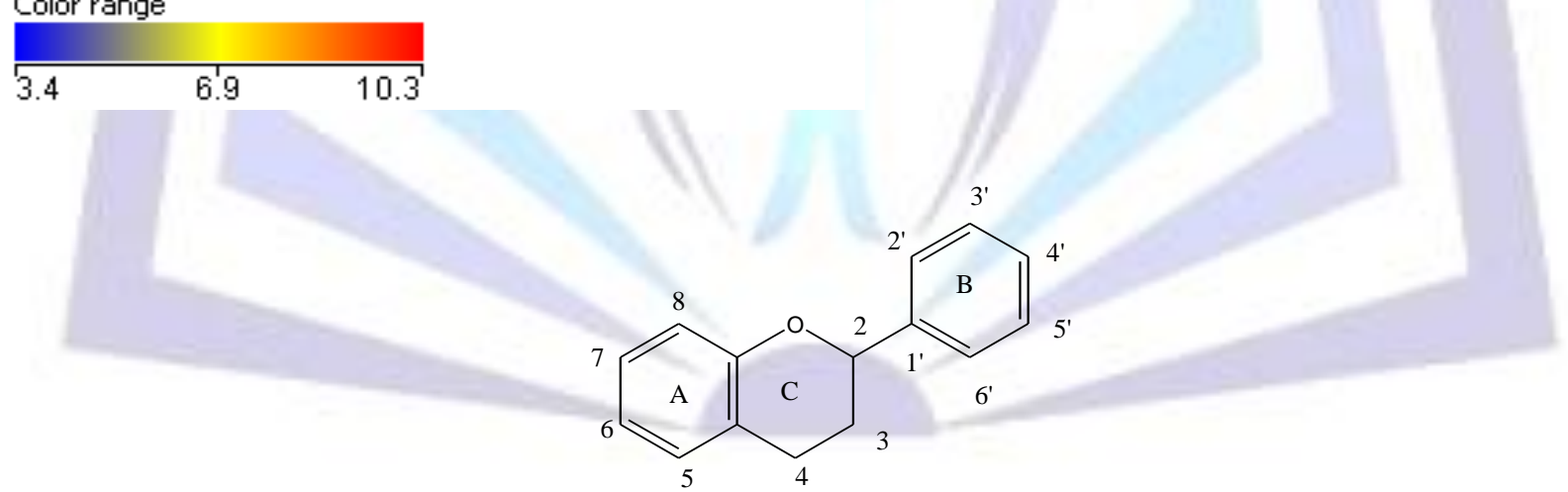

Fig. 3. General Structure of Flavonoid

\section{CONCLUSION}

Flavonoid profiling of the Fd extracts using LCMS Q-TOF followed by HCA clustering generated a dendrogram representing four clusters of flavonoids distribution in the eight samples, which were grouped based on their distribution values represented by colour intensity. The identified flavonoids were epicatechin, myricetin and naringenin along with two flavonoid glucosides identified as quercetin 5,4'-di-O-beta- $D$-glucopyranoside and quercetin-3-rutinoside. Except for epicatechin, the other four flavonoids have not been reported to occur in any Fd species. A high amount of epicatechin found in Fdvd (leaf and fig) and Fdvi (fig) may be responsible for the strong radical scavenging activities found in the 
extract. This is also supported by our previous study which found strong antioxidant and neuroprotective effects for the same two plant varieties [10].

\section{ACKNOWLEDGMENTS}

We gratefully acknowledge the reviewers for providing valuable comments for improving the manuscript. This work was financially supported by the Ministry of Higher Education (MOHE) Research Grant Scheme-600-RMI/ST/FRGS5/3/Fst $(227 / 2010)$.

\section{REFERENCES}

[1] Abas, F., Lajis, N.H., Israf, D.A., Khozirah, S., \& Umi Kalsom, Y., (2006). Antioxidant and Nitric Oxide Inhibition Activities of Selected Malay Traditional Vegetables. Food Chem. 95: 566-573

[2] Adam, Z., Hamid, M., Ismail, A., \& Khamis, S., (2007). Effect of Ficus deltoidea Aqueous Extract on Blood Glucose Level in Normal and Mild Diabetic Rats. Malaysian Journal Health Science 5 (2), 9-16

[3] Agilent Technologies, (2003). Time-of-Flight Mass Spectrometry. Agilent Literature P/N: 5989-0373ENSanta Clara, CA, USA

[4] Ahmad, R., Ali, A.M., Israf, D.A., Ismail, N.H., Shaari, K., \& Lajis, N.H., (2005). Antioxidant, Radical-Scavenging, Anti-Inflammatory, Cytotoxic and Antibacterial Activities of Methanolic Extracts of Some Hedyotis Species. Life Sciences 1953-1964

[5] Almahy, H.A., Rahmani, M., Sukari, M.A., \& Ali, A.M., (2003). The Chemical Constituents of Ficus benjamina Linn. and Their Biological Activities. Pertanika J. Sci. Technol., 11(1): 73-81

[6] Ao, C., Higa, T., Ming, H., Ding, Y., \& Tawata, S., (2010). Isolation, Identification of Antioxidant and Hyaduronidase Inhibitory Compounds from Ficus microcarpa L.fil. Bark. Journal of Enzyme Inhibition on Medicinal Chemistry, 406413

[7] Birt, D.F., Hendrich, S., \& Wang, W., (2001). Dietary Agents in Cancer Prevention: Flavonoids and Isoflavonoids. Pharmacology \& Therapeutics2-3, 157-177

[8] Dajas, F., Rivera, F., Blasina, F., Arredondo, F., Echeverry, C., Lafon, L., Morquio, A., \& Heinzen, H., (2003). Cell culture protection and in vivo neuroprotective capacity of flavonoids. Neurotoxicity Research, 5:377-384

[9] Din, L., Yusoff, N.K., Samsudin, M.W., Suki, U., Mat Salleh, K., Ibrahim, A.Z., Latiff, A., \& Said, I.M., (2002). A preliminary phytochemical survey of plants in Crocker range, Sabah, Malaysia. Asean Review of Biodiversity and Environmental Conservation (ARBEC)

[10] Dzolin, S., Ahmad, R., Mat Zain M., \& Syed Aris. S.R., (2012). Inhibition of Free Radical and Neuroprotective Effect of Four Varieties of Ficus deltoidea. Journal of Advanced Materials Research Vols. 554-556. Trans Tech Publications,Switzerland. Digital Object Identifier:10.4028/www.scientific.net/AMR.554-556.1371

[11] Esposito, E., Rotilio, D., Di Matteo, V., Di Giulio, C., Cacchio, M., \& Algeri, S., (2002). A review of specific dietary antioxidants and the effects on biochemical mechanisms related to neurodegenerative processes. Neurobiology of Aging, 23: 719-735

[12] Fukusaki, E., \& Kobayash, A., (2005). Plant Metabolomics: Potential for Practical Operation. Journal of Bioscience And Bioengineering. Vol. 100, No. 4, 347-354

[13] Galati, G., \& O'brien , P.J., (2004). Potential Toxicity of Flavonoids and Other Dietary Phenolics: Significance for Their Chemopreventive And Anticancer Properties. Free Radical Biology \& Medicine 287 - 303, 2004

[14] Hakiman, M., Arif Syed, M., Syahida, A., \& Maziah, M., (2012). Total Antioxidant, Polyphenol, Phenolic acid, and Flavonoid Content in Ficus deltoidea Varieties. Journal of Medicinal Plants Research Vol. 6(33), 4776-4784

[15] Hakiman, M., \& Maziah, M., (2009). Non Enzymatic and Enzymatic Antioxidant Activities in Aqueous Extract of Different Ficus deltoidea Accessions. Journal of Medicinal Plants Research 120-131

[16] Heim, K., Tagliaferro, A., \& Bobilya, D., (2002). Flavonoid Antioxidants: Chemistry, Metabolism and Structure. Journal of Nutritional Biochemistry 572-584

[17] Huang, Z., X. Cai, C. Shao, Z. She and X. Xia et al., (2008). Chemistry and Weak Antimicrobial Activities of Phomopsins Produced by Mangrove Endophytic Fungus Phomopsis sp. ZSU-H76. Phytochemistry, 69: 1604-1608

[18] Kamalakkannan, N., \& Prince, P.S, (2006). Antihyperglycaemic and antioxidant effect of rutin, a polyphenolic flavonoid, in streptozotocin-induced diabetic wistar rats. Basic Clin Pharmacol Toxicol 98:97-103

[19] Markham, K. R., Ternai, B., Stanley, R., Geiger, H., \& Mabry, T. J., (1978). ${ }^{13}$ C-NMR Studies of Flavonoids II. Tetrahedron. 34:1391-1397

[20] Mat-Salleh, K., \& Latiff, A., (2002). Dikotiledon: Subkelas Hamamelidae. Ficus deltoidea Jack. In Tumbuhan Ubatan Malaysia. Research Managemant Centre, Universiti Kebangsaan Malaysia pp: 184-185 
[21] Nurulain, T.Z., (2006). Green Tea and Its Polyphenolic Catechins: Medicinal Uses in Cancer Noncancer Applications. Life Sciences, 18:2073-2080

[22] Omar, M.H., Mullen, W., \& Crozier, A., (2011). Identificationof Proanthocyanidin Dimmers and Trimers, Flavones Cglycosides and Antioxidants in Ficus deltoidea, a Malaysian Herbal Tea. J.Agric. Food Chem 54, 1363-1369

[23] Ortiz-Andrade, R.R., Torres-Piedra, M., Sánchez-Salgado, J.C., García-Jimenez, S., Villalobos-Molina, R., Ibarra-Barajas, M., Gallardo-Ortiz, I., \& Estrada-Soto, S., (2008). Acute and Sub-chronic Effects of Cochlospermum vitifolium in Blood Glucose Levels in Normoglycemic and STZ-nicotinamide-induced Diabetic Rats. Revista Latinoamericana de Química ,37:122-132

[24] Pyrzanowska, J., Piechal, A., Blecharz-Klin, K., Joniec-Maciejak, I., Zobel, A., \& Widy-Tyszkiewicz, E., (2012). Influence of long-term administration of rutin on spatial memory as well as the concentration of brain neurotransmitters in aged rats. Pharmacol Rep 64:808-16

[25] Ross, J.A., \& Kasum, C.M., (2002). Annual Rev. Nutr. 22, 19-34

[26] Siti Fatimah Zahra, M.A., Mahmood, M.A., Hapipah, M.A., Suzita, M.N. \& Salmah, I. (2009). Anti-Ulcerogenic Activity of Aqueous Extract of F. deltoidea Against Ethanol-Induced Gastric Mucosal Injury In Rats. Research Journal of Medical Sciences 3(2): 42-46

[27] Sulaiman, M.R., Hussain, M.K., Zakaria, Z.A., Somchit, M.N., Moin, S., Mohamad, A.S., \& Israf, D.A., (2008). Evaluation of the Antinociceptive Activity of Ficus deltoidea Aqueous Extract. Fitoterapia 557-561

[28] Tagashira, M., \& Ohtake, Y., (1998). A New Antioxidative 1,3-benzodioxole from Melissa officinalis. Planta Medica 555-558

[29] Thurman, E.M., (2003). Liquid chromatography/time-of-flight/mass spectrometry (LC/TOF/MS) for the analysis of emerging contaminants. TrAC Trends in Analytical Chemistry, 750-756

[30] Tomsone, L., Kruma, Z., Alsina, I., \& Lepse, L., (2012). The application of hierarchical cluster analysis for clasifying horseradish genotypes (Armoracia rusticana L.) roots. ISSN $1392-1231$. Cheminè Technologija. Nr. 4 (62)

[31] Uebanso, T., Arai, H., Taketani, Y., Fukaya, M., Yamamoto, H., Mizuno, A., Uryu, K., Hada, T. \& Takeda, E. (2007). Extracts of Mimordica charantia suppress postprandial hyperglycemia in rats. J. Nutr. Sci. Vitaminol. 53: $482-488$

[32] Vaya, J., \& Mahmood, S., (2006). Flavonoid Content in Leaf Extracts of the Fig (Ficus carica L.), Carob (Ceratonia siliqua L.) and Pistachio (Pistacia lentiscus L.). Biofactors, 28, 169-75

[33] Williams, R.J., Spencer, J.P.E., \& Rice-Evans, C., (2004). Antioxidants or Signalling Molecules?. Free Radical Biology and Medicine 36 (7), 838-849

[34] Wollenweber, E., (1982). The Occurrence of Favanones in the Farinose Exudates of the Fern Onychium siliculosum. Phytochemistry 21, 1462-1464

[35] Wu, T., Guan, Y., \& Ye, J., (2011). Determination of Flavonoids and Ascorbic Acid in Grapefruit Peel and Juice by Capillary Electrophoresis with Electrochemical Detection. Food Chemistry

[36] Zakaria, Z.A., Hussain, M.K., Mohamad, A.S., Abdullah, F.C., \& Sulaiman, M.R., (2011). Antiinflammatory Activity of Aqueous Extract of Ficus deltoidea. Biological Research for Nursing. DOI: 10.1177/1099800410395378

[37] Zhishen, J., Mengcheng, T., \& Jianming, W., (1999). The Determination of Flavonoid Contents in Mulberry and Their Scavenging Effects on Superoxide Radicals. Food Chemistry 555-559

[38] Zunoliza, A., Khalid, H., Zhari, I., Rasadah, M.A., Mazura, M.P., Fadzureena, J., \& Rohana, S., (2009). Evaluation of extracts of Leaf of Three Ficus deltoidea Varieties for Antioxidant Activities and Secondary Metabolites. Phcog. Res. 1:216-223

[39] Malayan Forest Records No. 26., (1978). Tree Flora of Malaya (Vol.3). Forest Research Institute, Kepong, Malaysia 145 